\title{
Gallstone ileus diagnosis and treatment: six-year experience in three academic institutions
}

\begin{abstract}
Background: Gallstone ileus is defined as a mechanical intestinal obstruction due to impaction of one or more gallstones within the gastrointestinal tract. It occurs most frequently in elderly patients, and accounts for $1 \%-4 \%$ of mechanical intestinal obstructions. The mainstay of treatment is surgical exploration.

Methods: We present a retrospective review of patients with gallstone ileus, treated during 2015-2020, in three western academic centers in Mexico. The aim of this study was to describe the clinical manifestations, radiological and operative findings, surgical treatment and postoperative outcomes.

Results: The study included sixteen patients. Seventy five percent of patients were female and the overall median age was 55 years (range 26-81). Clinical presentation included abdominal pain $(93.7 \%)$, vomit $(81.2 \%)$, abdominal distention and impossibility to pass feces and flatus $(68.7 \%)$. Classical image findings were observed on plain abdominal radiographs (43.7\%), ultrasound (37.5\%) and computed tomography $(81.2 \%)$. All patients underwent surgical treatment. The terminal ileum was the most common site of impaction (75\%). The most frequent fistula was cholecystoduododenal (75\%). Enterotolithotomy alone was performed in $68.7 \%$ of patients, and one-stage-procedure in $31.2 \%$. Overall morbidity rate and morality rates were $75 \%$ and $12.5 \%$, respectively.
\end{abstract}

Conclusions: Gallstone ileus is a rare cause of gastrointestinal obstruction, with female and elderly population preponderance, although younger patients are affected. A high clinical index of suspicion guides image modality selection, where CT is the most useful image used. Enterolithotomy alone is the most frequent surgical approach, with a lower morbidity rate. Indications for a one-stage surgical approach remain to be established.

Keywords: biliary fistula, ileus, biliary calculi, intestinal obstruction, cholelithiasis
Volume I 3 Issue I - 2022

Itzé Aguirre-Olmedo, 1,2 Santiago Rea-Alvarez del Castillo, ,2 Carlos M Nuño-Guzmán, 2,3 Alberto Briceño-Fuentes,' Román I GarcíaGonzález, ${ }^{4}$ M Carmen Torres-González, ${ }^{1,2}$ Felipe Ferrari-Ulloa,' A Rebecca JuárezGonzález, ${ }^{3}$ C Alfredo Bautista-Lopez',2

'Department of General Surgery, Nuevo Hospital Civil de Guadalajara “Juan I. Menchaca”, México

${ }^{2}$ Centro Universitario de Ciencias de la Salud, Universidad de Guadalajara, México

${ }^{3}$ Department of General Surgery, Antiguo Hospital Civil de Guadalajara "Fray Antonio Alcalde", México

${ }^{4}$ Department of General Surgery, Hospital General de Occidente, México

Correspondence: Itzé Aguirre-Olmedo. Department of General Surgery. Universidad de Guadalajara Nuevo Hospital Civil de Guadalajara "Juan I. Menchaca". Salvador Quevedo y Zubieta 750, Independencia Oriente, C.P. 44340, Guadalajara, Jalisco, México, Tel +52 3339424400 ,

Email dra.itze.aguirre.gastrocirugia@gmail.com

Received: October 07, 202I | Published: January II, 2022

\section{Introduction}

Gallstone ileus (GI) is an infrequent complication of cholelithiasis and is defined as a mechanical intestinal obstruction due to impaction of one or more gallstones within the gastrointestinal tract. ${ }^{1}$ This complication occurs most frequently in elderly patients. It develops in $0.3 \%-0.5 \%$ of patients with cholelithiasis and accounts for $1 \%-4 \%$ of mechanical intestinal obstructions. ${ }^{2,3}$ GI is frequently preceded by an initial episode of acute cholecystitis. The impacted gallstone causes mucosal ischemia and necrosis, which further erodes through the gallbladder wall and leads to fistula formation between the gallbladder and an adhered portion of the gastrointestinal tract, with subsequent gallstone passage. ${ }^{4,5}$ The majority of gallstones smaller than $2-2.5 \mathrm{~cm}$ will pass spontaneously through a normal gastrointestinal tract. Larger gallstones may suffer impaction and cause intestinal obstruction. The most common site of impaction is the terminal ileum and the ileocecal valve. $^{1}$

The mainstay of treatment is surgical exploration, with enterolithotomy alone, or a one-stage procedure consisting of enterolithotomy, cholecystectomy and fistula repair in selected cases, as surgical options. ${ }^{6}$ Here we present a retrospective review of patients with GI diagnosis, treated during a 6-year period in three western academic centers in Mexico. The aim of this study was to describe the clinical manifestations, radiological and operative findings, surgical procedures and postoperative outcomes of patients with GI.

\section{Materials and methods}

\section{Patient population and study variables}

We conducted a retrospective review of medical records for patients at three western Mexican academic institutions (Hospital Civil de Guadalajara Juan I. Menchaca, Guadalajara, Jalisco; Hospital Civil de Guadalajara Fray Antonio Alcalde, Guadalajara, Jalisco; Hospital General de Occidente, Zapopan, Jalisco) that underwent surgical treatment for GI between January 2015 and December 2020.

Patient data collection included demographics, preoperative comorbidities, clinical presentation, diagnostic workup, time interval from diagnosis to surgical treatment, surgical findings, details of the surgical procedure and postoperative complications.

The study was approved by the Committees of Human Research of each participant institution and was conducted in accordance with the principles of the Declaration of Helsinki.

\section{Diagnostic and therapeutic approach}

All patients were initially treated as a gastrointestinal obstruction, with fasting, volume resuscitation, and placement of a nasogastric tube in patients with severe bowel distension and vomiting. Diagnostic workup started with laboratory tests, plain abdominal radiographies, followed by ultrasound and computed tomography (CT) as needed.

All patients were surgically treated with an exploratory laparotomy and either enterolithotomy alone or a one-stage procedure of enterolithotomy plus cholecystectomy and fistula repair, according to surgeons' decision.

\section{Statistical analysis}

Continuous data are presented as means \pm standard deviation (SD) or medians (range). Qualitative variables are presented as frequencies 
and percentages for qualitative variables. Statistical analysis was performed using R software version 4.0.2 (Vienna, Austria).

\section{Results}

During a six-year period, sixteen patients underwent surgical intervention for GI. Seventy five percent of patients were female and the overall median age was 55years (range 26-81). The most common comorbidity found in our patients was systemic arterial hypertension (56.2\%), followed by diabetes mellitus (37.5\%), and obesity (31.2\%). Fifty percent and $37.5 \%$ of our patients had an American Society of Anesthesiologist (ASA) class III and class II physical status, respectively (Table 1 ).

Table I Demographic characteristics, comorbidities and ASA classification of 16 patients with gallstone ileus

\begin{tabular}{ll}
\hline Variables & All patients $(\boldsymbol{n}=\mathbf{~ I 6})$ \\
\hline Age (years) & $55(26-8 \mathrm{I})$ \\
Gender (females) & $12(75 \%)$ \\
Comorbidities & \\
Hypertension & $9(56.2 \%)$ \\
Diabetes mellitus & $6(37.5 \%)$ \\
Obesity & $5(31.2 \%)$ \\
CHF & I $(6.2 \%)$ \\
Hemolytic anemia & I (6.2\%) \\
ASA classification & \\
I & $2(12.5 \%)$ \\
II & $6(37.5 \%)$ \\
III & $8(50 \%)$ \\
\hline
\end{tabular}

\section{Clinical, laboratory, and radiological findings}

The median time for diagnosis from onset of symptoms was 6days (range 2-28days). Clinical presentation included abdominal pain in 15 patients $(93.7 \%)$, followed by vomit in 13 patients $(81.2 \%)$, abdominal distention and impossibility to pass feces and flatus in 11 patients $(68.7 \%)$. Less common symptoms were fever in two patients and jaundice in one patient (Table 2).

Table 2 Clinical, laboratorial and radiological findings of 16 patients with gallstone ileus

\begin{tabular}{|c|c|}
\hline Variables & All patients $(n=16)$ \\
\hline Days from onset of symptoms to diagnosis & $6(2-28)$ \\
\hline \multicolumn{2}{|l|}{ Clinical findings } \\
\hline Abdominal pain & 15 (93.7\%) \\
\hline Vomit & 13 (8I.2\%) \\
\hline Constipation & II (68.7\%) \\
\hline Abdominal distension & II (68.7\%) \\
\hline Fever & $2(12.5 \%)$ \\
\hline Hemolytic anemia & I (6.2\%) \\
\hline Jaundice & I (6.2\%) \\
\hline \multicolumn{2}{|l|}{ Laboratory } \\
\hline Electrolyte abnormalities & I 4 (87.5\%) \\
\hline Abnormal LFTs & $5(31.2 \%)$ \\
\hline \multicolumn{2}{|l|}{ Radiological findings } \\
\hline Radio-opaque gallstone & II (68.7\%) \\
\hline Bowel distension & $10(62.5 \%)$ \\
\hline Pneumobilia & $8(50 \%)$ \\
\hline
\end{tabular}

Laboratory tests showed electrolyte imbalance in 14 patients $(87.5 \%)$ and liver function tests abnormalities in five patients $(31.2 \%)$. A correct preoperative diagnosis of GI was reached in 13 patients $(81.2 \%)$; the remaining was diagnosed during surgery. The classical image signs of GI were visualized in 7 patients $(43.7 \%)$ on plain abdominal radiograph (Figure 1), in six patients $(37.5 \%)$ on ultrasound (Figure 2) (Figure 3), and in 13 patients (81.2\%) on CT (Figure 4) (Figures 5a \& b).

Image findings included radio-opaque image suggestive of a gallstone in 11 patients $(68.7 \%$ ), (Figure 6) bowel distention in 10 patients $(62.5 \%)$ (Figure 7 ), and pneumobilia in 8 patients $(50 \%)$ (Figure 8), all classical signs of Rigler's triad. ${ }^{7}$

One 80years-old female with gastric outlet obstruction syndrome was diagnosed through a gastroduodenoscopy where the gallstone was found in the second portion of duodenum. (Figures 9A \& B) An endoscopic attempt to extract the stone failed, so she was surgically intervened. Table 3 shows the details of our study population (Table 3).

\section{Operative findings}

All patients underwent surgical treatment. Impacted gallstone was located in the terminal ileum in 12 patients $(75 \%)$, in duodenum in two patients (12.5\%), followed by stomach and jejunum, each in one patient $(6.2 \%)$. The median number of intraluminal gallstones was 1 (range 1-6) with a median size of $3.6 \mathrm{~cm}$ (range 2-8cm). The site of bilioenteric fistula was documented during surgery in 14 patients $(87.5 \%)$. Due to severe inflammation in the right upper quadrant, it could not be documented in the rest of them. Cholecystoduododenal fistula was the most common type (75\%) of our patients, followed by cholecystogastric fistula (12.5\%) (Table 3).

During exploratory laparotomy, enterotolithotomy alone was performed in 11 patients $(68.7 \%)$; two of such enterolithotomies were performed in the duodenum followed by simple duodenorraphy, due to poor clinical conditions of the patients. In one patient the gallstone was extracted through a gastrotomy. An intestinal resection and anastomosis was needed to extract the stone and remove an ischemic ileum segment in one patient. In the remaining 12 patients the procedure was completed with enterotomy and transverse enterorraphy (Figure 10).

A Meckel's diverticulum was incidentally found in an 81years-old female but since it was not complicated, no surgical management was needed (Figure 11). One-stage-procedure was performed in 5 patients $(31.2 \%)$. No patient was managed with a two-stage procedure. Median intraoperatory blood loss was $110 \mathrm{ml}$ (range 40-350), median surgical time was 100 minutes (range 53-230), and median hospital stay was 7 days (range 1-17).

\section{Morbidity and mortality}

The overall morbidity rate was $75 \%$ since complications occurred in 12 out of 16 patients. Twenty five percent of patients had pneumonia, $18.7 \%$ developed acute renal failure, $12.5 \%$ had a pleural effusion or atelectasia, and $12.5 \%$ showed signs of dehiscence of the duodenal enterorraphy performed during surgery. Sixty two percent of patients developed other complications including superficial surgical site infection, fluid sterile collection, mild acute pancreatitis, and poor glycemic control. Two patients $(12.5 \%)$ died as a consequence of sepsis due to enterorraphy dehiscence. According to the ClavienDindo Classification. ${ }^{8}$, complications, $50 \%$ were classified as grade II, $31.25 \%$ as grade I, $12.5 \%$ as grade V, and $6.2 \%$ as grade IIIb. Mean follow-up was 291 days (range 4 to 1460). During this time, there were no cases of recurrent GI or other late biliary complications. Table 4 shows the treatment details and outcomes of our patients. (Table 4). 
Table 3 Demographic characteristics, comorbidities,ASA classification, diagnostic method, surgical procedure, site of obstruction, postoperative morbidities and Clavien-Dindo classification of 16 patients with gallstone ileus

\begin{tabular}{|c|c|c|c|c|c|c|c|c|}
\hline $\begin{array}{l}\text { Gender I } \\
\text { age (years) }\end{array}$ & Comorbidities & $\begin{array}{l}\text { ASA } \\
\text { score }\end{array}$ & $\begin{array}{l}\text { Onset of } \\
\text { symptoms } \\
\text { (days) }\end{array}$ & $\begin{array}{l}\text { Diagnostic } \\
\text { method }\end{array}$ & $\begin{array}{l}\text { Surgical } \\
\text { procedure }\end{array}$ & $\begin{array}{l}\text { Site of } \\
\text { obstruction }\end{array}$ & Morbidity & $\begin{array}{l}\text { Clavien- } \\
\text { Dindo }\end{array}$ \\
\hline$M / 50$ & $\begin{array}{l}\text { DM Hemolytic } \\
\text { anemia }\end{array}$ & II & 6 & $\begin{array}{l}\text { Plain } \\
\text { abdominal } \\
\text { radiograph, } \\
\text { CT }\end{array}$ & Enterolithotomy & Stomach & None & $\mathrm{I}$ \\
\hline$F / 26$ & Obesity & II & 8 & US, CT & Enterolithotomy & Ileum & $\begin{array}{l}\text { Enterorraphy } \\
\text { dehiscence }\end{array}$ & $3 b$ \\
\hline$F / 49$ & None & II & 2 & US, CT & Enterolithotomy & Ileum & None & 1 \\
\hline$F / 69$ & DM, SAH & III & 2 & US, CT & $\begin{array}{l}\text { Enterolithotomy } \\
+ \\
\text { cholecystectomy } \\
+ \text { fistula closure }\end{array}$ & Ileum & Pneumonia & 2 \\
\hline \multirow[t]{2}{*}{$M / 63$} & $\mathrm{SAH}, \mathrm{CHF}$ & III & 2 & US & $\begin{array}{l}\text { Enterolithotomy } \\
+ \\
\text { cholecystectomy } \\
+\end{array}$ & Jejunum & $\begin{array}{l}\text { Pleural } \\
\text { effusion }\end{array}$ & 2 \\
\hline & & & & & fistula closure & & & \\
\hline$F / 78$ & DM, SAH & III & 4 & $\begin{array}{l}\text { Plain } \\
\text { abdominal } \\
\text { radiograph }\end{array}$ & Enterolithotomy & Ileum & $\begin{array}{l}\text { Pneumonia, } \\
\text { Death }\end{array}$ & 5 \\
\hline$F / 8 I$ & DM, SAH & III & 10 & $\begin{array}{l}\text { Plain } \\
\text { abdominal } \\
\text { radiograph, } \\
\text { CT }\end{array}$ & $\begin{array}{l}\text { Enterolithotomy } \\
+ \text { intestinal } \\
\text { resection and } \\
\text { anastomosis }\end{array}$ & Ileum & $\begin{array}{l}\text { Pneumonia, } \\
\text { pleural } \\
\text { effusion, acute } \\
\text { renal failure, } \\
\text { SSI }\end{array}$ & 2 \\
\hline$M / 72$ & SAH & II & 4 & $\begin{array}{l}\text { Plain } \\
\text { abdominal } \\
\text { radiograph, } \\
\text { CT }\end{array}$ & Enterolithotomy & Ileum & $\begin{array}{l}\text { Acute renal } \\
\text { failure }\end{array}$ & 2 \\
\hline F / 49 & Obesity & I & 4 & $\begin{array}{l}\text { Plain } \\
\text { abdominal } \\
\text { radiograph, } \\
\text { CT }\end{array}$ & Enterolithotomy & Ileum & None & $\mathrm{I}$ \\
\hline$M / 47$ & None & I & 9 & $\begin{array}{l}\text { Plain } \\
\text { abdominal } \\
\text { radiograph, } \\
\text { US, CT }\end{array}$ & Enterolithotomy & Ileum & None & I \\
\hline F / 5 I & Obesity & III & 12 & US, Plain & $\begin{array}{l}\text { Enterolithotomy } \\
+\end{array}$ & Ileum & Seroma & 2 \\
\hline & & & & $\begin{array}{l}\text { abdominal } \\
\text { radiograph }\end{array}$ & $\begin{array}{l}\text { cholecystectomy } \\
+ \text { fistula closure }\end{array}$ & & & \\
\hline F / 59 & SAH, Obesity & III & 28 & $\mathrm{CT}$ & Enterolithotomy & Ileum & Pneumonia & 2 \\
\hline$F / 48$ & SAH & II & 16 & $\mathrm{CT}$ & Enterolithotomy & Ileum & Seroma & I \\
\hline$F / 67$ & $\begin{array}{l}\text { DM, SAH, } \\
\text { Obesity }\end{array}$ & III & 20 & $\mathrm{CT}$ & $\begin{array}{l}\text { Enterolithotomy } \\
+ \\
\text { cholecystectomy } \\
+ \text { fistula closure }\end{array}$ & Duodenum & $\begin{array}{l}\text { Acute renal } \\
\text { failure, } \\
\text { glycemic } \\
\text { disorder }\end{array}$ & 2 \\
\hline $\mathrm{F} / 40$ & DM & III & 3 & $\mathrm{CT}$ & $\begin{array}{l}\text { Enterolithotomy } \\
+ \\
\text { cholecystectomy } \\
+ \text { fistula closure }\end{array}$ & Ileum & $\begin{array}{l}\text { Diabetic } \\
\text { ketoacidosis }\end{array}$ & 2 \\
\hline$F / 80$ & SAH & II & 7 & EGD & Enterolithotomy & Duodedum & $\begin{array}{l}\text { Enterorraphy } \\
\text { dehiscence, } \\
\text { death }\end{array}$ & 5 \\
\hline
\end{tabular}

M, male; F, female; DM, diabetes mellitus; SAH, systemic arterial hypertension; CHF, congestive heart failure; CT, computed tomography; US, ultrasonography; EGD, esophagogastroduodenoscopy; SSI, surgical site infection 
Table 4 Treatment and outcomes of 16 patients with gallstone ileus

\begin{tabular}{|c|c|}
\hline Variables & All patients $(n=16)$ \\
\hline Correct preoperative diagnosis & $13(82.1 \%)$ \\
\hline \multicolumn{2}{|l|}{ Location of impacted gallstone } \\
\hline Stomach & I (6.2\%) \\
\hline Duodenum & $2(12.5 \%)$ \\
\hline lleum & $13(81.2 \%)$ \\
\hline Number of intraluminal gallstones & $I(I-6)$ \\
\hline Size of intraluminal gallstones $(\mathrm{cm})$ & $3.6(2-8)$ \\
\hline \multicolumn{2}{|l|}{ Location of bilioentérica fistula } \\
\hline Cholecystogastric & $2(12.5 \%)$ \\
\hline Cholecystoduodenal & $12(75 \%)$ \\
\hline Not documented & $2(12.5 \%)$ \\
\hline \multicolumn{2}{|l|}{ Surgical procedure } \\
\hline Enterolithotomy & II (68.7\%) \\
\hline $\begin{array}{l}\text { Enterolithotomy }+ \text { cholecystectomy }+ \\
\text { fistula closure }\end{array}$ & $5(31.2 \%)$ \\
\hline \multicolumn{2}{|l|}{ Additional surgical procedure } \\
\hline Duodenotomy & $2(12.5 \%)$ \\
\hline Gastrotomy & I (6.2\%) \\
\hline Intestinal resection and anastomosis & I (6.2\%) \\
\hline Intraoperative blood loss (ml) & $110(40-350)$ \\
\hline Surgical time (min) & $100(53-230)$ \\
\hline \multicolumn{2}{|l|}{ Early postoperative complications } \\
\hline Pneumonia & $4(25 \%)$ \\
\hline Acute renal failure & $3(18.7 \%)$ \\
\hline Pleural effusion / atelectasia & $2(12.5 \%)$ \\
\hline Dehiscence of enterorraphy & $2(12.5 \%)$ \\
\hline Others & $10(62.5 \%)$ \\
\hline Death & $2(12.5 \%)$ \\
\hline \multicolumn{2}{|l|}{ Clavien-Dindo Classification } \\
\hline Grade I & $5(31.2 \%)$ \\
\hline Grade II & $8(50 \%)$ \\
\hline Grade IIIb & I (6.2\%) \\
\hline Grade V & $2(12.5 \%)$ \\
\hline Hospital stay (days) & $7(1-17)$ \\
\hline Follow-up (days) & $291(4-1460)$ \\
\hline \multicolumn{2}{|c|}{$\begin{array}{l}\text { - } \mathrm{cm} \text { centimeters, } \mathrm{ml} \text { milliliters, } \text { min minutes } \\
\text { - Continuous variables are presented as median and range } \\
\text { - Qualitative variables are presented as number and percentage } \\
\text { - Follow-up (days) is presented as mean and range }\end{array}$} \\
\hline
\end{tabular}

\section{Discussion}

Gallstone ileus (GI) is a true mechanical obstruction caused by a biliary calculus that migrates from an inflamed gallbladder to the adjacent intestinal tract. ${ }^{5}$. Thomas Bartholin described the first case of GI en 1654, during a necropsy. In 1841, Bonnet presented the first case of duodenal obstruction in the duodenal bulb (Bouveret's syndrome). In 1890, Courvoisier published the first 131 cases of GI; 125 of such patients were operated, with a mortality of $44 \% .{ }^{9}$

GI is a rare complication of gallstone disease that most frequently occurs in elderly patients, with an occurrence of $0.3-0.5 \%$ in patients with cholecystolithiasis. ${ }^{2,3}$ This entity causes only $1 \%$ to $5 \% \%$ of all cases of mechanical bowel obstructions, but may be responsible for up to $25 \%$ of cases of small bowel obstruction in patients older than 65 years, with a female preponderance. ${ }^{10-12}$

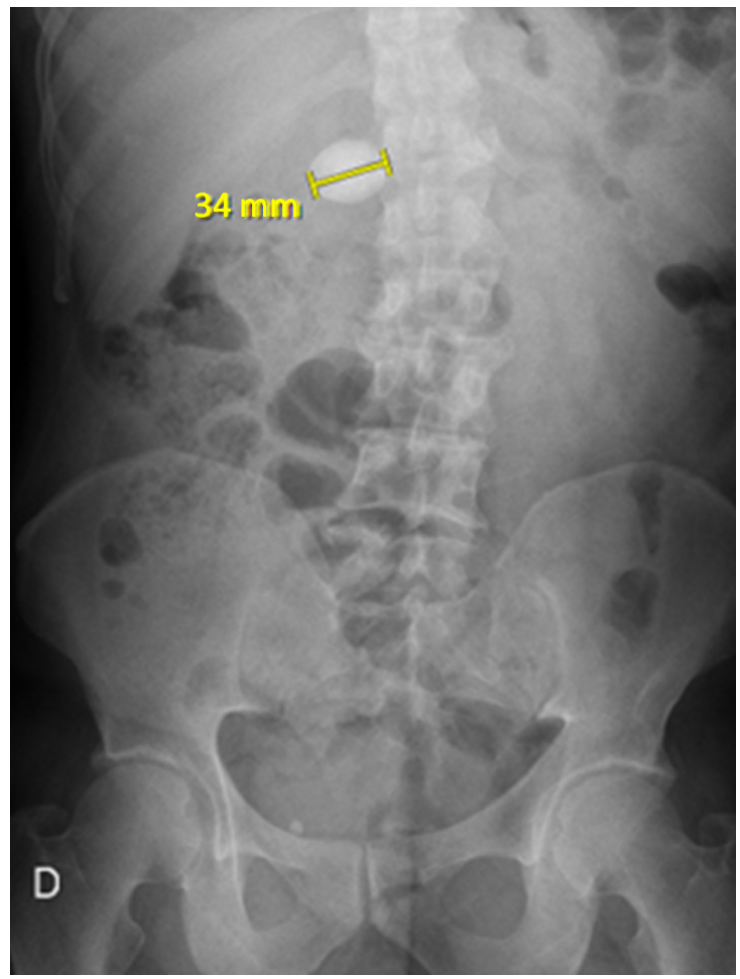

Figure I Plain abdominal radiograph showing a radio-opaque $34 \mathrm{~mm}$-image located in the right upper quadrant suggestive of a gallstone.

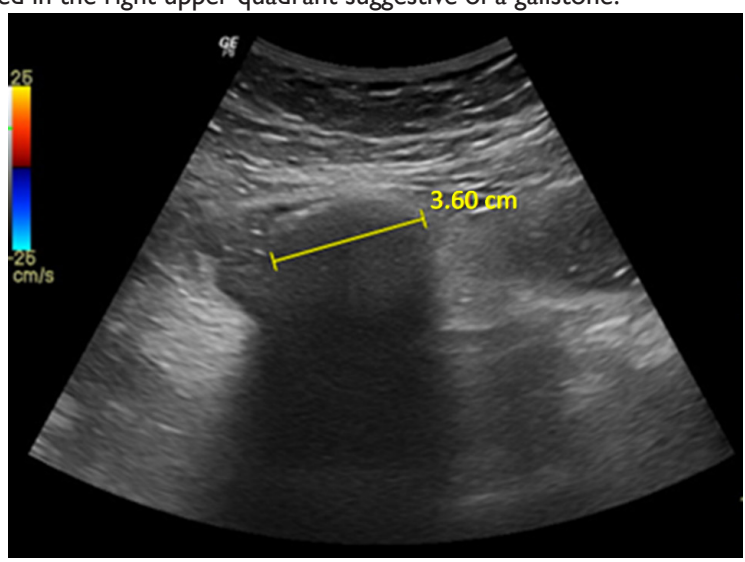

Figure 2 Abdominal ultrasound shows a hyperechoic oval-shaped image of $3.6 \mathrm{~cm}$ with acoustic shadow suggestive of a gallstone located in the right lower quadrant of the abdomen.

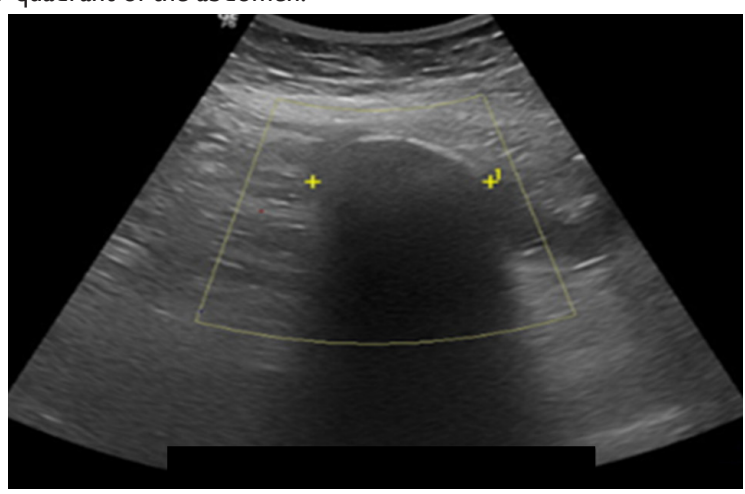

Figure 3 Abdominal ultrasound reveals an endoluminal hyperechoic roundshaped image with acoustic shadow located lateral to mesogastrium. 


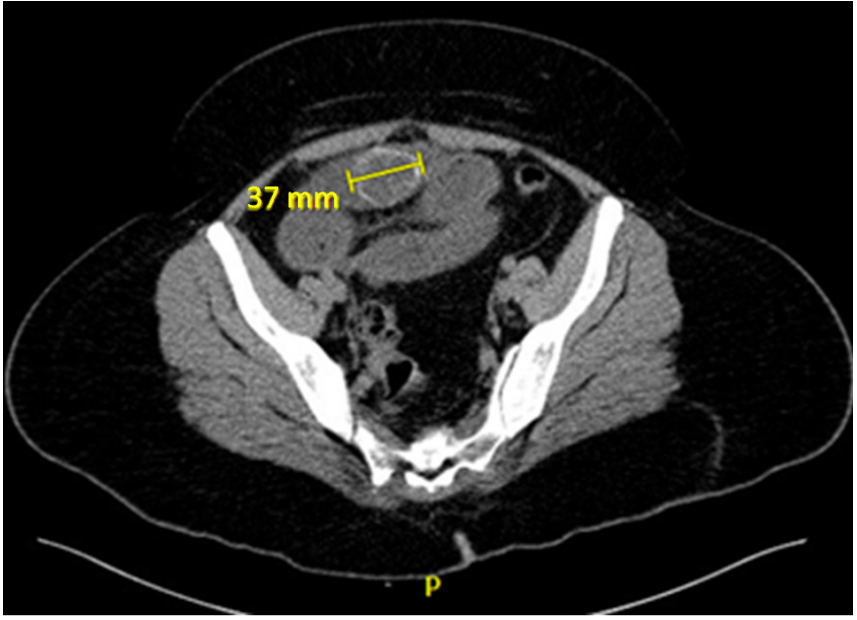

Figure 4 Computed tomography depicts an endoluminal oval-shaped image with calcium density, consistent with a migrated gallstone within the terminal ileum.
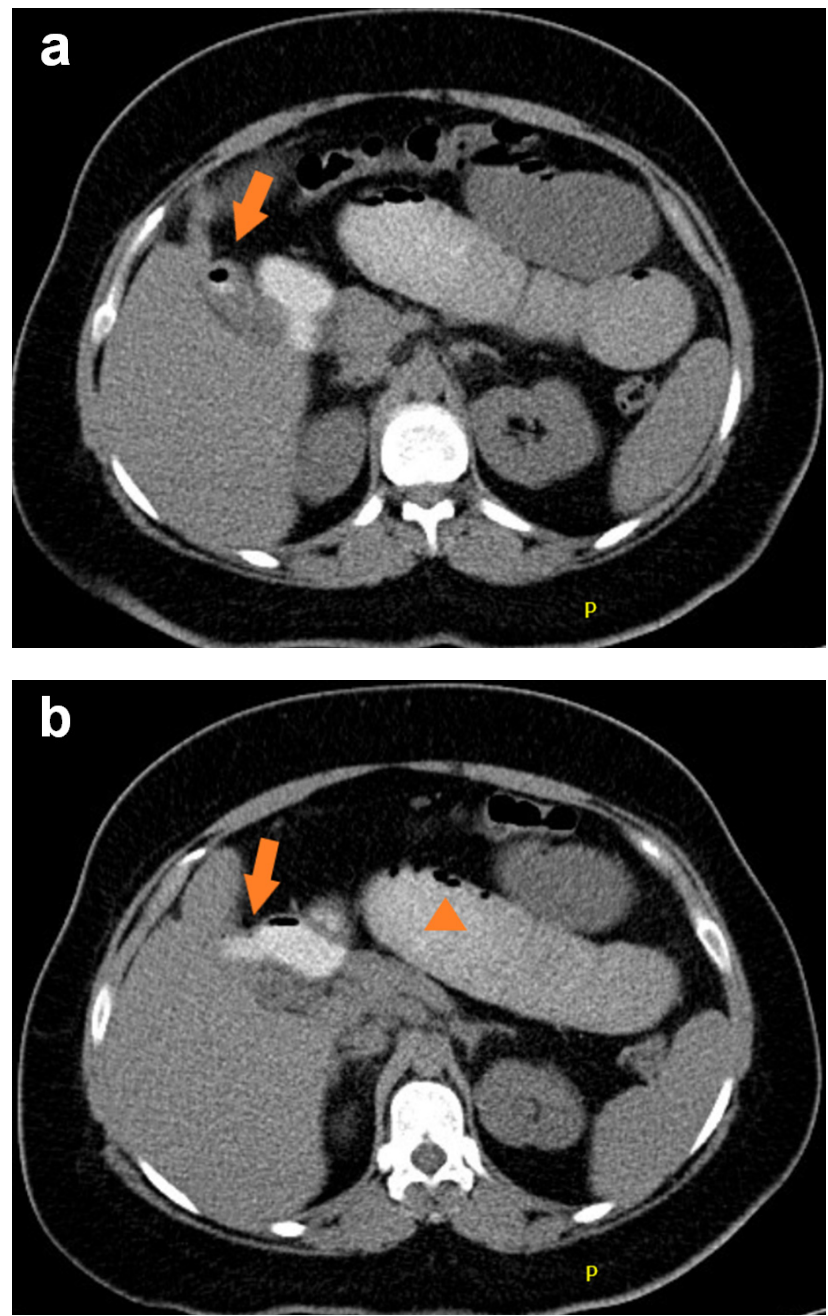

Figure 5A \& 5B Oral contrast-enhanced computed tomography findings in a patient with gallstone ileus. $a$. Gas observed within the gallbladder (arrow) b. Communication between a non-distended gallbladder and the duodenum, where presence of oral contrast is observed in the site of the fistula (arrow), and fluid-filled dilated jejunal loops and intestinal pneumatosis (arrowhead).

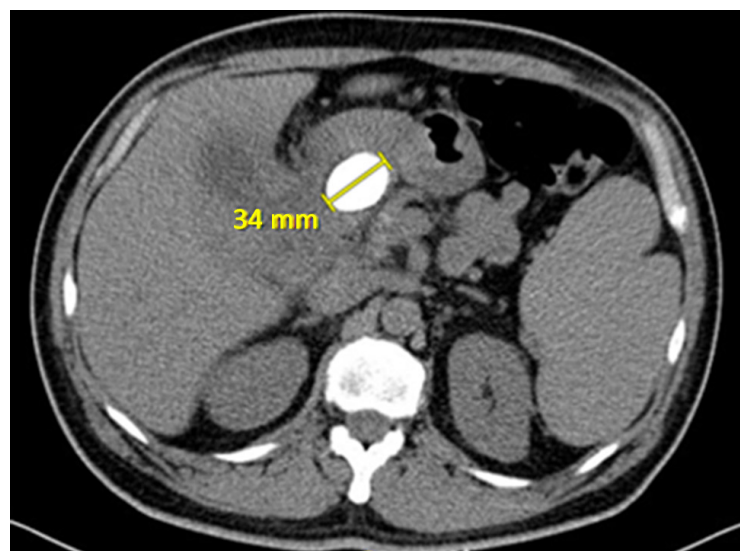

Figure 6 Computed tomography reveals a calcium density endoluminal foreign body of $34 \mathrm{~mm}$, located in the topography of the duodenum.

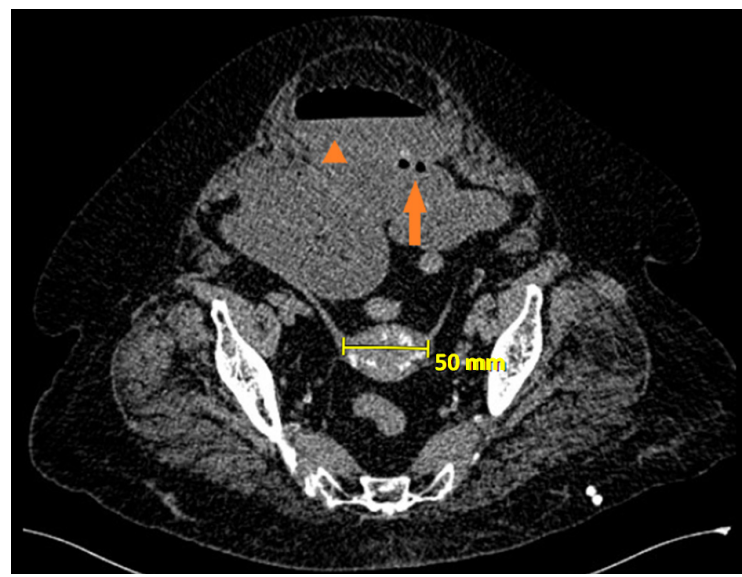

Figure 7 Fluid-filled dilated intestinal loops and hydro-air level (arrowhead), intestinal pneumatosis (arrow), and an endoluminal round-shaped calciumdensity image of $50 \mathrm{~mm}$ are seen.

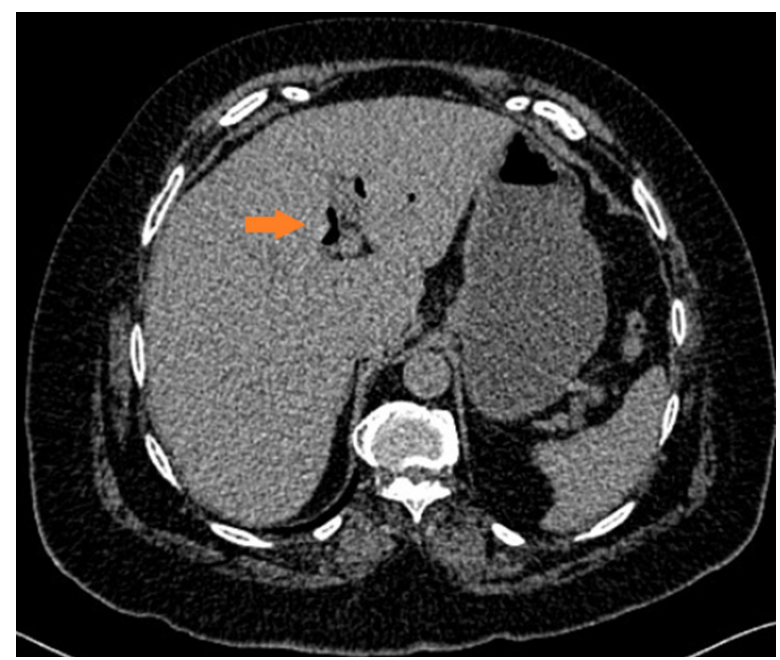

Figure 8 Computed tomography shows pneumobilia (arrow) as part of Riegler's Triad.

In the present series, the median age was 55 years, and $37.5 \%$ of our patients were 50years old or less. Elderly patients constitute the majority of cases with GI, but patients in the third and fourth decade of life have also been observed in recent series. ${ }^{6,13,14}$ In our series we only had one patient 26years old with GI. 

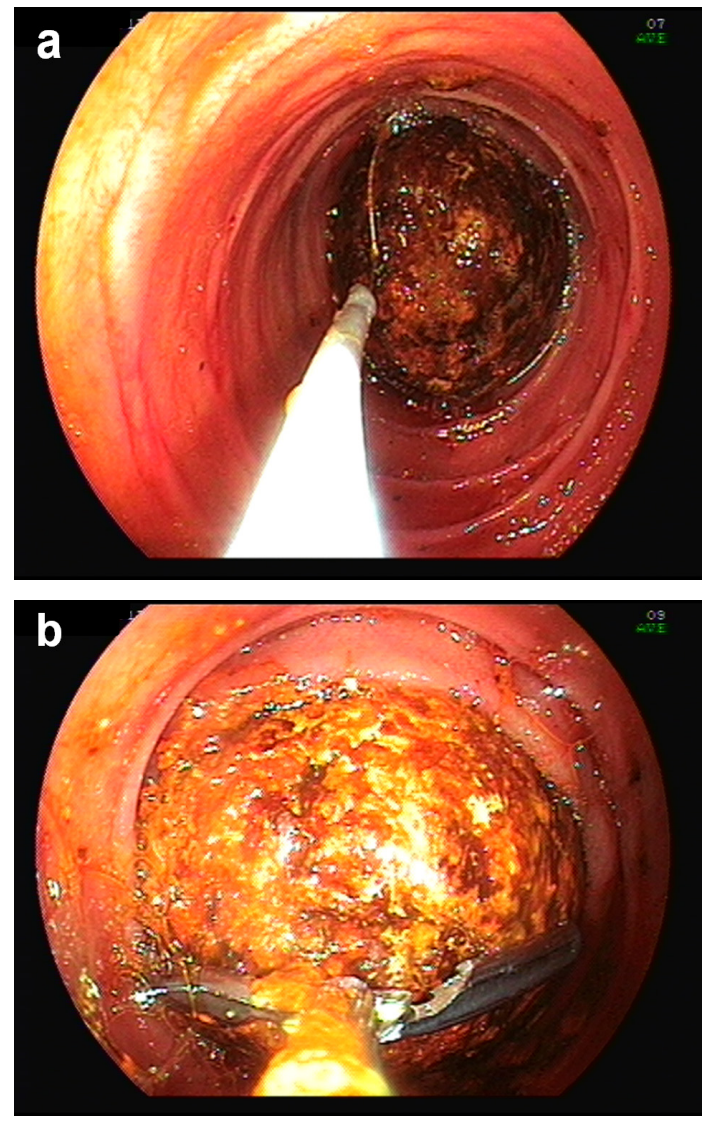

Figure 9 Endoscopic findings during a gastroduodenoscopy performed to a patient with Bouveret's syndrome. $a$. Gallstone impacted within the 2 nd portion of duodenum showing a failed attempt to extract it with a Roth net. b. A rat-tooth retrieval forceps.

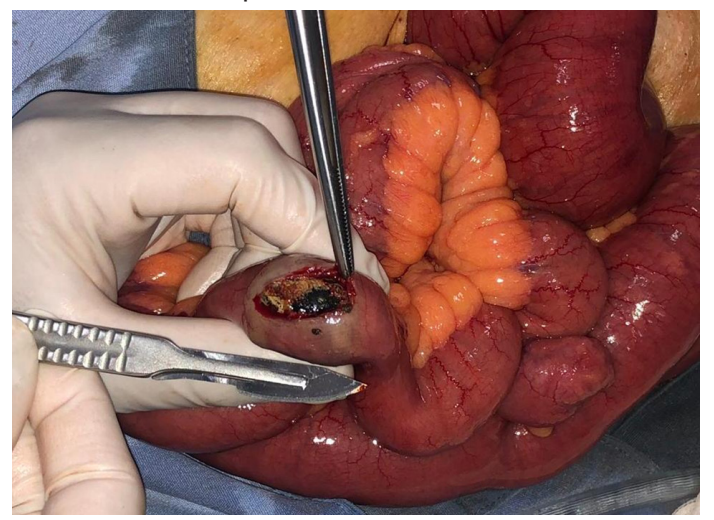

Figure 10 Surgical findings in a patient with gallstone ileus. Enterotomy performed over the site of the impacted gallstone in the terminal ileum.

Clinical presentation of gallstone ileus has not changed in a long time. The classic presentation is an older female patient with episodic subacute obstruction. There are three forms of presentation: acute, subacute, or chronic (Karewsky's syndrome). This clinical presentation may be given depending on the site of obstruction and the size of the gallstone. ${ }^{15}$ Diagnosis of GI can be challenging due to several factors: the intermittency of the symptoms, the fact that signs and symptoms are nonspecific, the advanced age of the patients and their concomitant diseases. ${ }^{11,16}$ The median time to reach diagnosis from onset of symptoms was 6days (range 2-28 days). The majority of patients present 4 to 8 days after the onset of symptoms, which include crampy abdominal pain, nausea, and vomiting. Other signs and symptoms are jaundice $(<15 \%)$, abdominal distension and fever. ${ }^{16}$ This is consistent with the clinical manifestations of our patients in whom we found abdominal pain, vomiting, abdominal distention, and impossibility to pass stools and gas in more than $60 \%$ of cases, fever in $12.5 \%$, and jaundice in 1 patient $(6.25 \%)$ only. We also had two patients with Bouveret's syndrome and classical symptoms of gastric outlet obstruction (early satiety, epigastric pain, nausea, nonbilious vomiting, anorexia) but none with upper gastrointestinal bleeding caused by erosion of the duodenum by the impacted gallstone, as other authors have reported. ${ }^{16}$

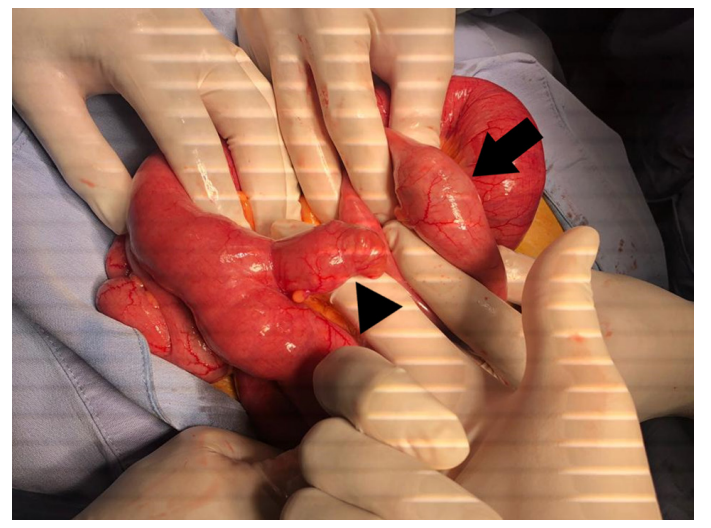

Figure I I Surgical findings in patient with gallstone ileus. a. Segment of ileum at $60 \mathrm{~cm}$ from the ileocecal valve with non-complicated Meckel's diverticulum (arrowhead) and site of impacted gallstone in ileum, at $50 \mathrm{~cm}$ from the ileocecal valve (arrow).

Obstruction of the bowel usually occurs after the impaction of a gallstone at least $2.5 \mathrm{~cm}$ in diameter. Clavien et al. reported the size of obstructing gallstone from 2 to $5 \mathrm{~cm} .{ }^{3}$ Nakao et al. found a range gallstone size of $2-10 \mathrm{~cm} .{ }^{14}$ In our patients the median size of gallstones was $3.6 \mathrm{~cm}$ (range $2-8 \mathrm{~cm}$ ). Usually, a single intraluminal gallstone can be located during surgery. ${ }^{15}$ Cases of multiple gallstones have been reported in 3 to $40 \%$ of cases. ${ }^{3,17}$ Surgeons are encouraged to palpate and explore the whole bowel length in search for more than one gallstone, which could cause recurrent GI episodes. ${ }^{1,16}$ In our series, multiple gallstones were found and extracted in three patients, two gallstones in two patients, and six gallstones in one patient. No recurrent GI episodes were documented during follow-up.

The most common sites of gallstone impaction is the ileum $(0 \%$ $89.5 \%)$, followed by the jejunum $(0 \%-50 \%)$, stomach $(0 \%-20 \%)$, duodenum $(0 \%-10.5 \%)$, and colon $(0 \%-8.1 \%) .{ }^{16,18}$ In our series, we found a similar frequency of gallstone impaction, as the majority was found in the ileum $(81.2 \%)$, followed by the duodenum $(12.5 \%)$ and the stomach in one case $(6.2 \%)$.

Gallstone migration from the gallbladder to the gastrointestinal tract occurs more frequently through a cholecystoduodenal fistula, with rates in the range of $32.5 \%-96.5 \%$ of cases. ${ }^{16,19}$ In our patients the cholecystoduodenal fistula was the most common location site of gallstone migration $(75 \%)$, followed by a cholecystogastric fistula $(12.5 \%)$. Due to severe inflammation in the right upper abdominal quadrant, identification of fistula could not be achieved in the remaining $12.5 \%$ of cases. Other sites of bilioenteric fistula have been described at the right or transverse colon, jejunum, and even more rare locations such as duodeno-left hepatic biliary duct. ${ }^{5,9,20}$

Radiologic workup is crucial for the diagnosis of GI. The Rigler's $\operatorname{Triad}^{7}$ of pneumobilia, ectopic radio-opaque gallstone and intestinal distension, is variably found on plain abdominal radiographs in 17$87 \%$ of cases. ${ }^{9}{ }^{21}$ Balthazar and Schechter described another sign 
consisting of the presence of two fluid-filled loops in the right upper quadrant: the medial one corresponding to the duodenal bulb and the lateral one to the gallbladder, due to the presence of air within this organ. ${ }^{22}$ Abdominal ultrasound can also provide useful information, which includes the presence of bilioenteric fistula, a gallstone impacted within the bowel, gastric distension as seen in Bouveret's syndrome, and residual gallstones within the gallbladder or choledocholithiasis, being these two last findings the most valuable ones, since this would encourage the surgeon to consider cholecystectomy and even bile duct exploration during surgical treatment. ${ }^{9,18,21}$ Ultrasound is also considered highly sensitive for pneumobilia and ectopic gallstones, but in cases of complete bowel obstruction the exam can be technically difficult to perform, due to patient discomfort and intraluminal gas interposition. ${ }^{18}$ The combination of ultrasound and plain radiographs increases the sensitivity of GI diagnosis to $74 \% .^{18,21,23}$

Contrast-enhanced abdominal CT represents the best radiologic method to diagnose GI, with $93 \%$ sensitivity and $100 \%$ specificity. ${ }^{24}$ Additional signs that can be found on abdominal CT are changes in the gallbladder wall suggestive of chronic cholecystitis, location of bilioenteric fistula and size and location of intraluminal gallstones. ${ }^{9}$ In our series, we found an ectopic radio-opaque gallstone in $68.75 \%$, bowel distension in $62.5 \%$, and pneumobilia in $50 \%$ of cases, with the combined diagnostic workup of plain radiographs, abdominal ultrasound, and CT. A correct preoperative diagnosis has been reported in other series between $30 \%$ and $75 \%$ of cases. ${ }^{16}$ In our patients we were able to make this correct preoperative diagnosis of GI in 13 patients $(81.2 \%)$.

Surgery is the standard approach for gallstone ileus. Its main objective is to relieve the intestinal obstruction once hydro-electrolytic correction and hemodynamic stabilization have been achieved. Three possible procedures have been described: enterolithotomy alone, one stage surgery that consists of enterolithotomy plus cholecystectomy plus fistula repair, and two-stage surgery that involves enterolithotomy alone, with a second surgical event to repair the fistula and perform cholecystectomy. Enterolithotomy alone is the most commonly performed procedure. ${ }^{15,16}$ An enterotomy in the antimesenteric border over the offending gallstone is performed and transverse enterorraphy in a Heineke-Mikulicz fashion is recommended to avoid stenosis. ${ }^{2,3}$ This surgical approach was performed in $68.75 \%$ of our patients. One-stage surgery has been advocated for patients with hemodynamic stability and with low surgical risk (ASA I and II). This approach has the advantage of preventing recurrent GI and other late biliary complications associated to an unsolved cholecystolithiasis: cholecystitis, cholangitis, acute pancreatitis, choledocholithiasis and gallbladder carcinoma. ${ }^{16}$ We performed such one-stage approach in $31.25 \%$ of our patients. We treated 11 of our patients $(68.7 \%)$ with enterolithotomy alone and after a mean follow-up of 291days, there were no cases of recurrent GI or other late biliary complications.

There have been conflicting results regarding the morbidity and mortality of the three different surgical approaches used to treat GI. Simple enterolithotomy has been associated with lower morbidity and mortality compared to the one-stage procedure according to some authors. ${ }^{10,25}$ Although other authors prefer the one-stage surgery, when patients in different surgical groups were comparable in terms of age, concomitant diseases and APACHE II score, operative morbidity and mortality rates have not been significantly different. ${ }^{3}$. Other studies have reported a higher morbidity among patients treated with the one-stage procedure, even when the ASA scores were similar for both groups of patients. ${ }^{25}$ Thus, the one-stage procedure should be performed in highly selected patients who have been adequately reanimated and have absolute indications for biliary surgery at presentation, such as acute cholecystitis, gallbladder necrosis or residual gallstones. . $^{3,10,11,14,26}$

Postoperative complications have been estimated in the range of $45 \%$ to $69 \%$. The most common postoperative complications are surgical site infection, followed by acute renal failure, pneumonia, urinary tract infection and anastomotic leaks., 15,16,26-28 In our series, we report an overall morbidity rate of $75 \%$ (12 patients). This is rate is higher than those reported by other authors, but $50 \%$ of complications in our series corresponded to Clavien-Dindo I, which might be underestimated in many series. In our series, complications were documented in $60 \%$ of patients treated by enterolithotomy alone, and $100 \%$ of patients managed with a one-stage surgery. This might be related to a higher median age in the one-stage surgery group of patients ( 65 years, range $40-81$, vs. 49 years, range 26-80). The ASA classification was also higher among patients in the one-stage surgery group, where $100 \%$ had an ASA score of III. More patients in the one-stage surgery group were affected by SAH (66\% vs. $50 \%)$, DM $(66 \%$ vs. $25 \%)$ and obesity $(33.3 \%$ vs. $20 \%)$. Similar results have been reported by previous series.

Mortality rate ranges from $0 \%$ to $24 \%{ }^{12,15,25,27,29}$ Higher mortality rates have been associated to major proportion of elderly patients among those affected by GI, their concomitant diseases and agerelated surgical complications. ${ }^{16}$ The one-stage surgical approach has been independently associated to mortality. ${ }^{12}$ When analyzed by surgical procedure, mortality rate is higher for the one-stage surgery group $(0 \%-15 \%)$ than for the enterolithotomy alone group $(0 \%-$ $25 \%)^{12,15,25,29,30}$ When bowel resection is required due to vascular compromise at the site of gallstone impaction, mortality rates from $13 \%$ to $50 \%$ have been reported. ${ }^{12,30}$ In our series, one patient with a gallstone impacted in the ileum required resection and anastomosis. The patient developed pneumonia, pleural effusion, acute renal failure, and surgical site infection, but finally recovered.

The present study examined the diagnostic and therapeutic approach of patients with GI in three academic hospitals in the same city, over a 6-year period. The present study has several limitations. The retrospective design constitutes the main limitation. The second one is the reduced number of patients that resembles the low number of patients in most series and the low frequency of presentation of this clinical entity. Ideally, randomized controlled clinical trials would be needed to establish the best surgical approach, which could be difficult to perform in the clinical scenario.

\section{Conclusions}

Gallstone ileus is a rare cause of gastrointestinal obstruction, with female and elderly population preponderance, although younger patients are affected. A high clinical index of suspicion guides image modality selection, where CT is the most useful image study used. An adequate preoperative stabilization and optimization of comorbidities will allow a better outcome. Surgical relief of gastrointestinal obstruction is the cornerstone of treatment. Enterolithotomy alone is the most frequent su.rgical approach and has a lower morbidity rate. Indications for a one-stage surgical approach remain to be established.

\section{Acknowledgments}

None.

\section{Conflicts of interest}

The authors declare that they have no conflicts of interest. 


\section{Author contributions}

\section{Design of the study: Itzé Aguirre-Olmedo}

Data acquisition and analysis and interpretation of data: Itzé Aguirre-Olmedo, Santiago Rea-Alvarez del Castillo, Carlos M. Nuño-Guzmán, Alberto Briceño-Fuentes, Román I. García-González, M Carmen Torres-González, Felipe Ferrari-Ulloa, A. Rebecca JuárezGonzález.

Drafting of the manuscript: Itzé Aguirre-Olmedo, Santiago ReaÁlvarez-del-Castillo, Carlos M. Nuño-Guzmán, Román I. GarcíaGonzález, M Carmen Torres-González, Felipe Ferrari-Ulloa.

Manuscript writing: Itzé Aguirre-Olmedo, Santiago Rea-Álvarezdel-Castillo, Carlos M. Nuño-Guzmán.

\section{Funding}

This Research work was supported by Universidad de Guadalajara.

\section{References}

1. Abou-Saif A, Al-Kawas FH. Complications of gallstone disease: Mirizzi syndrome, cholecystocholedochal fistula, and gallstone ileus. Am J Gastroenterol. 2002;97(2):249-254.

2. Kurtz RJ, Heimann TM, Beck AR, et al. Patterns of treatment of gallstone ileus over a 45-year period. Am J Gastroenterol 1985;80(2):95-98.

3. Clavien PA, Richon J, Burgan S, et al. Gallstone ileus. Br J Surg. 1990;77(7):737-742.

4. Beltran MA, Csendes A. Mirizzi syndrome and gallstone ileus: an unusual presentation of gallstone disease. J Gastrointest Surg. 2005;9(5):686-689.

5. Scuderi V, Adamo V, Naddeo M, et al. Gallstone ileus: monocentric experience looking for the adequate approach. Updates Surg. 2018;70:503-511.

6. Mir SA, Hussain Z, Davey CA, et al. Management and outcome of recurrent gallstone ileus: A systematic review. World J Gastrointest Surg. 2015;7(8):152-159.

7. Rigler LG, Borman CN. Gallstone obstruction. Pathogenesis and Roentgen manifestations. JAMA. 1941;117(21):1753-1759.

8. Dindo D, Demartines N, Clavien PA. Classification of surgical complications: a new proposal with evaluation in a cohort of 6336 patients and results of a survey. Ann Sur. 2004;240(2):205-213.

9. Beuran M, Ivanov I, Venter MD. Gallstone ileus-clinical and therapeutic aspects. J Med Life. 2010;3(4):365-371.

10. Reisner RM, Cohen JR. Gallstone ileus: a review of 1001 reported cases. Am Surg. 1994;60(6):441-446.

11. Ayantunde AA, Agrawal A. Gallstone ileus: diagnosis and management. World J Surg. 2007;31(6):1292-1297.

12. Halabi WJ, Kang CY, Ketana N, et al. Surgery for gallstone ileus: a nationwide comparison of trends and outcomes. Ann Surg. 2014;259(2):329-335.
13. Moberg AC, Montgomery A. Laparoscopically assisted or open enterolithotomy for gallstone ileus. Br J Surg 2007;94(1):53-57.

14. Nakao A, Okamoto Y, Sunami M, et al. The oldest patient with gallstone ileus: report of a case and review of 176 cases in Japan. Kurume Med J. 2008;55(1-2):29-33.

15. Gallstone Ileus: results of analysis of a series of 40 patients. Gastroenterol Hepatol. 2001;24(10):489-94.

16. Nuño-Guzmán CM, Marín-Contreras ME, Figueroa-Sánchez M, et al. Gallstone ileus, clinical presentation, diagnostic and treatment approach. World J Gastrointest Surg. 2016;8(1):65-76.

17. Salazar-Jiménez MI, Alvarado-Durán J, Fermín-Contreras MR, et al. Gallstone ileus, surgical management review. Cir Cir. 2018;86(2):182186.

18. Chang L, Chang M, Chang HM, et al. Clinical and radiological diagnosis of gallstone ileus: a mini review. Emerg Radiol. 2018;25(2):189-196.

19. Nuño-Guzmán CM, Arróniz-Jáuregui J, Moreno-Pérez PA, et al. Gallstone ileus: One-stage surgery in a patient with intermittent obstruction. World J Gastrointest Surg. 2010;2(5):172-176.

20. Stagnitti F, Tudisco A, Ceci F, et al. Biliodigestive fistulae and gallstone ileus: diagnostic and therapeutic considerations. Our experience. $G$ Chir. 2014;35(9-10):235-238.

21. Zaliekas J, Munson JL. Complications of gallstones: the Mirizzi syndrome, gallstone ileus, gallstone pancreatitis, complications of "lost" gallstones. Surg Clin North Am. 2008;88(6):1345-1368.

22. Balthazar EJ, Schechter LS. Air in gallbladder: a frequent finding in gallstone ileus. Am J Roentgenol. 1978;131(2):219-222.

23. Ripollés T, Miguel-Dasit A, Errando J, et al. Gallstone ileus: increased diagnostic sensitivity by combining plain film and ultrasound. Abdom Imaging. 2001;26(4):401-405.

24. Yu CY, Lin CC, Shyu RY, et al. Value of CT in the diagnosis and management of gallstone ileus. World $J$ Gastroenterol. 2005;11(14):2142-2147.

25. Doko M, Zovak M, Kopljar M, et al. Comparison of surgical treatments of gallstone ileus: preliminary report. World J Surg. 2003;27(4):400404.

26. Ravikumar R, Williams JG. The operative management of gallstone ileus. Ann R Coll Surg Engl. 2010;92(4):279-281.

27. Rodríguez-Sanjuán JC, Casado F, Fernández MJ, et al. Cholecystectomy and fistula closure versus enterolithotomy alone in gallstone ileus. $\mathrm{Br} J$ Surg 1997;84(5):634-637.

28. García-Marín A, Pérez-López M, Pérez-Bru S, et al. Gallstone ileus, an uncommon cause of bowel obstruction. Rev Gastroenterol Mex. 2014;79(3):211-213.

29. Tan YM, Wong WK, Ooi LL. A comparison of two surgical strategies for the emergency treatment of gallstone ileus. Singapore Med J. 2004;45(2):69-72.

30. Martínez Ramos D, Daroca José JM, Escrig Sos J, et al. Gallstone ileus: management options and results on a series of 40 patients. Rev Esp Enferm Dig. 2009;101(2):117-120. 